Check for updates

Cite this: RSC Adv., 2017, 7, 20766

Received 6th February 2017

Accepted 29th March 2017

DOI: $10.1039 / \mathrm{c} 7 \mathrm{ra01532a}$

rsc.li/rsc-advances

\section{Construction of biomimetic long-circulation delivery platform encapsulated by zwitterionic polymers for enhanced penetration of blood-brain barrier $\dagger$}

\author{
Nan Wang, (D) Xin Jin (ID * and Xinyuan Zhu (D)*
}

The effective treatments for central nervous system (CNS) diseases are impeded mostly by the existence of the blood-brain barrier (BBB). The accumulation of therapeutic drugs inside the brain is far from the therapy threshold, which is closely related to the transient circulation time of drugs and their carriers. Herein, a core-shell protein-based long-circulation delivery platform was constructed. Through in situ free radical polymerization, a zwitterionic polymer poly(2-methacryloyloxyethyl phosphorylcholine) (PMPC) was modified on the surface to prolong the circulation lifetime with a biomimetic structure induced by a phosphorylcholine (PC) head-group similar to the lipids in the outer membrane of living cells. A cellpenetrating peptide, HIV-1 trans-activating transcriptor (TAT) was conjugated on the surface of the protein-based nanoparticles, endowing the delivery platform with BBB-crossing ability. The BBBpermeability of the nanoparticles was investigated both in vitro and in vivo. Encapsulated with zwitterionic polymer PMPC, the nanoparticles showed a long circulation lifetime due to strong resistance to nonspecific adsorption and provided a better chance for BBB penetration. The delivery platform had enhanced permeability for BBB and a longer retention time inside the brain in a healthy mouse model. Overall, the surface modification with zwitterionic polymer PMPC and cell-penetrating peptide TAT changes the circulation modality of the nanoparticles in vivo, and provides a promising pathway for BBB crossing as a potential drug delivery platform for CNS related disease therapy.

\section{Introduction}

Central nervous system (CNS) related diseases have an increasing occurrence now due to the aging of the population. However, effective therapies are greatly impeded by the strictly selective permeability of the blood-brain barrier (BBB). ${ }^{1-3}$ This high selectivity of the BBB results from the tight junctions (TJs) between endothelial cells in CNS capillaries, ${ }^{4}$ and the existence of P-glycoprotein (P-gp) on the cell membrane of brain capillaries which can rapidly pump the intrusive therapeutic agents out of the brain and back to the blood circulation. ${ }^{5}$ These specific features make it rather difficult for CNS therapeutic agents to reach the diseased brain sections or remain there for sufficient time. In recent years, various therapeutic BBB carriers have been developed for CNS diseases, ${ }^{6}$ such as chemical delivery systems, ${ }^{7,8}$ carrier-mediated transports, ${ }^{9-11}$ molecular Trojan horses, ${ }^{12-15}$ and colloidal carriers. ${ }^{16,17}$ However, the therapeutic efficacy of these delivery systems is barely

School of Chemistry and Chemical Engineering, State Key Laboratory of Metal Matrix Composites, Shanghai Jiao Tong University, 800 Dongchuan Road, Shanghai 200240, P. R. China.E-mail: jxcindy@sjtu.edu.cn; xyzhu@sjtu.edu.cn

$\dagger$ Electronic supplementary information (ESI) available: Experimental details and supplementary data. See DOI: 10.1039/c7ra01532a satisfactory from expectation, resulting from their limited penetration and retention ability. Therefore, the drug concentration in the diseased sections is much lower than the threshold for therapy. To address these problems, receptormediated BBB delivery systems have been considered as a powerful strategy to promote BBB penetration efficacy. Many researchers have focused on searching for specific receptors which are over-expressed on the BBB cell membrane to gain access to the brain with the required concentration for therapy. Various systems have been developed based on this assumption, including receptors for transferrin,${ }^{18}$ insulin, ${ }^{19}$ diphtheria toxin, ${ }^{20,21}$ and nicotinic acetylcholine. ${ }^{22-24}$ However, the BBB penetration efficiency is still not satisfactory due to factors such as the usually saturated binding sites under normal conditions in vivo. ${ }^{4}$

Learning from successful strategies for the treatment of tumors in other parts of the body, ${ }^{25,26}$ a prolonged circulation time of the delivery system is always able to enhance tumor targeting and accumulation. This seems to indicate that the circulation time of the delivery system may play a key role in BBB penetration. ${ }^{27-29}$ To one's surprise, the importance of the in vivo circulation ability of the BBB carriers has long been ignored in the treatment of CNS diseases. It is well known that 
PEGylation is the most widely used strategy to prolong the circulation lifetime of various delivery systems. Nevertheless, due to the progression of the immune response to the polyethylene glycol (PEG) shell and the significantly accelerated blood clearance, the therapeutic efficacy of PEGylated nanocarriers for CNS diseases is greatly restricted. ${ }^{30-35}$ In this respect, a novel delivery system with lower immune response and longer circulation time is urgently needed. Inspired by the excellent stability and long circulation ability of cells under blood circulation and normal physiological conditions, the composition of the outer bilayer membrane of living cells arouses the interest of many scientists. The biomembrane of cells is mainly constructed of natural phospholipid molecules. Therefore, it is reasonable to deduce that a material which can mimic this special structure will meet the requirements mentioned above to the greatest extent. Owing to its similar structure to the headgroup of phosphorylcholine (PC) lipids in the outer surface of living cells, the zwitterionic polymer poly(2-methacryloyloxyethyl phosphorylcholine) (PMPC) shows excellent hydrophilicity, biocompatibility, stability and bioavailability, which have even been confirmed clinically. ${ }^{36-39}$ PMPC encapsulation empowers the nanocarriers with a biomembrane-like structure, providing a biocompatible chemical structure which is the basis for an ability to circulate for a long time in the blood. ${ }^{40-42}$ Jiang and co-workers have demonstrated that PMPC shows a high non-fouling property of excellent resistance to nonspecific protein adsorption, which can reduce its quick recognition by the immune system and delay blood clearance. ${ }^{42-46}$ Consequently, coating with PMPC will endow the BBB delivery shuttles with a stealth property and therefore much longer circulation-lifetime in vivo with a better chance to contact with and penetrate through the BBB cell membrane.

As a proof of the concept whether circulation time is a key factor in $\mathrm{BBB}$ penetration, we report here for the first time a facile approach of constructing a protein-based biomimetic nanoplatform encapsulated with zwitterionic polymer PMPC and conjugated with HIV-1 trans-activating transcriptor (TAT) peptides to penetrate the BBB. The advantages of this delivery platform can be listed as follows: (1) encapsulation with PMPC endows the delivery shuttle with a stealth property and therefore much longer circulation-lifetime in vivo with little or even no immune response; ${ }^{47-56}$ (2) as the mechanism of TAT entering the CNS is the temporary disruption of the BBB mainly by decreasing the expression of and altering the distribution of TJs proteins, ${ }^{57-67}$ the delivery system conjugated with TAT can remain inside the brain parenchyma with reduced pumping back to blood circulation; (3) the model protein core can be replaced by any type of active protein, empowering the delivery system with additional therapeutic effects for different CNS diseases.

\section{Experimental}

\section{Materials}

Bovine serum albumin (BSA), 1-(3-dimethylaminopropyl)-3ethylcarbodiimide hydrochloride (EDC), dimethyl sulfoxide (DMSO), $\mathrm{CHCl}_{3}, \mathrm{HCl}$, trimethylamine and $\mathrm{NaHCO}_{3}$ were purchased from Aladdin Reagent Database Inc. (Shanghai, China). $N$-Hydroxy-succinimide ester (NAS), $N, N^{\prime}$-methylene bisacrylamide (BIS), ammonium persulfate (APS), acrylic acid (AA), 2-methacryloyloxyethyl phosphorylcholine (MPC), $N, N, N^{\prime}, N^{\prime}$-tetramethylethylenediamine (TEMED) and $N$-hydroxysuccinimide (NHS) were all purchased from Sigma-Aldrich Co. LLC. (USA). TAT (GRKKRRQRRRPP- $\mathrm{CH}_{3} \mathrm{O}$ ) was purchased from and synthesized by Shanghai Science Peptide Biological Technology CO., LTD. (Shanghai, China).

\section{Synthesis of TAT-modified BSA protein (TBSA)}

EDC $(4.3 \mathrm{mg})$ and NHS $(2.3 \mathrm{mg})$ were added to BSA solution $\left(0.5 \mathrm{mg} \mathrm{mL} \mathrm{m}^{-1}, 5.0 \mathrm{~mL}\right)$ and stirred for $3 \mathrm{~h}$. Then, $302.0 \mu \mathrm{L}$ of TAT $\left(1.0 \mathrm{mg} \mathrm{mL}^{-1}\right.$ in DMSO) was added to this mixture and stirred for another $3 \mathrm{~h}$. The solution was dialyzed (MWCO: $7000 \mathrm{Da})$ against $20 \mathrm{mM} \mathrm{PB}(\mathrm{pH}=7.4)$ for $48 \mathrm{~h}$ to give the TBSA nanoparticles.

\section{Synthesis of acryloylated BSA protein (aBSA)}

BSA protein was dissolved in $20 \mathrm{mM}$ pH 8.5 boric acid buffer (BB) solution to prepare a BSA solution with a concentration of $1.0 \mathrm{mg} \mathrm{mL}{ }^{-1} .31 .0 \mu \mathrm{L}$ of $1 \%(\mathrm{w} / \mathrm{w})$ DMSO solution of NAS was introduced to $13.3 \mathrm{~mL}$ of the above BSA solution. The mixture was stirred for $2 \mathrm{~h}$ at room temperature, and then dialyzed (MWCO: $7000 \mathrm{Da}$ ) against $20 \mathrm{mM}$ phosphate buffer $\mathrm{PB}(\mathrm{pH} 7.4$ ) solution for $48 \mathrm{~h}$ (fresh PB solution was replaced every $6 \mathrm{~h}$ ) to give an aBSA solution.

\section{Preparation of zwitterionic polymer capsuled protein-based nanogel (nBSA)}

The typical procedure for the preparation of zwitterionic polymer capsuled protein-based nanogel via in situ free radical polymerization directly on the surface of aBSA is described below: an aqueous solution of $118.1 \mathrm{mg}$ of MPC, $15.0 \mathrm{mg}$ of BIS, $29.4 \mu \mathrm{L}$ of TEMED and $5.0 \mathrm{~mL}$ of the above $0.5 \mathrm{mg} \mathrm{mL}^{-1}$ aBSA solution was added to a flask. The mixture was bubbled through nitrogen for $0.5 \mathrm{~h}$ to remove residual oxygen at room temperature. Then $11.0 \mathrm{mg}$ of APS was rapidly added and the polymerization was allowed to proceed for an additional $3 \mathrm{~h}$ in a nitrogen atmosphere at room temperature. Finally, dialysis (MWCO: $100 \mathrm{kDa}$ ) was used to remove monomers and initiators in $20 \mathrm{mM}$ PB solution ( $\mathrm{pH} 7.4$ ) for $48 \mathrm{~h}$ (fresh PB solution was replaced every $6 \mathrm{~h}$ ) to give an nBSA solution.

\section{Bioconjugation of TAT with zwitterionic nanogel (TAT-nBSA)}

The bioconjugation of cell penetrating peptide TAT with zwitterionic and protein-based nanogel was similar to that of BSA nanogel by modifying the protein-based nanogel using a conjugating technique. An aqueous solution of $118.1 \mathrm{mg}$ of MPC, $1.4 \mu \mathrm{L}$ of AA, $15.0 \mathrm{mg}$ of BIS, $29.4 \mu \mathrm{L}$ of TEMED and $5.0 \mathrm{~mL}$ of the above $0.5 \mathrm{mg} \mathrm{mL}^{-1}$ aBSA solution was added to a flask. The mixture was bubbled through nitrogen for $0.5 \mathrm{~h}$ to remove residual oxygen at room temperature. Then $11.0 \mathrm{mg}$ of APS was rapidly added and the polymerization was allowed to proceed for an additional $3 \mathrm{~h}$ in a nitrogen atmosphere at room 
temperature. Finally, dialysis (MWCO: $100 \mathrm{kDa}$ ) was used to remove monomers and initiators in $20 \mathrm{mM} \mathrm{PB}$ solution ( $\mathrm{pH} 7.4)$ for $48 \mathrm{~h}$ to give the nanogel acrylic nBSA. After that, EDC (4.3 $\mathrm{mg})$ and NHS $(2.3 \mathrm{mg})$ were added to the BSA-based nanogel solution $\left(0.5 \mathrm{mg} \mathrm{mL}{ }^{-1}, 5.0 \mathrm{~mL}\right)$ and stirred for $3 \mathrm{~h}$. Finally, different amounts of TAT (1.0 $\mathrm{mg} \mathrm{mL}^{-1}$ in DMSO) were added to this mixture and stirred for another $3 \mathrm{~h}(60.4 \mu \mathrm{L}$ of TAT for TAT1-nBSA, 302.0 $\mu \mathrm{L}$ of TAT for TAT-5-nBSA and $604.0 \mu \mathrm{L}$ of TAT for TAT-10-nBSA, where the number stands for the molar ratio of TAT to BSA). The solution was dialyzed (MWCO: $100 \mathrm{kDa}$ ) against $20 \mathrm{mM} \mathrm{PB}(\mathrm{pH}=7.4)$ for $48 \mathrm{~h}$ to give the final nanoparticles.

\section{Preparation of FITC labeled TAT}

$0.5 \mathrm{mg}$ of FITC was dissolved in $0.5 \mathrm{~mL}$ of $20 \mathrm{mM}$ PB solution (pH 8.5). $0.5 \mathrm{mg}$ of TAT was dissolved in $0.5 \mathrm{~mL}$ of DMSO. Then FITC solution was added dropwise to the TAT solution, stirred for $8 \mathrm{~h}$ at $4{ }^{\circ} \mathrm{C}$ and kept in a dark place. Subsequently the solution was dialyzed against $20 \mathrm{mM}$ PB solution ( $\mathrm{pH}$ 7.4) for 24 h (MWCO: $500 \mathrm{Da}$ ) and fresh PB solution was exchanged every 6 h. FITC labeled TAT was only used for experiments in Fig. $2 \mathrm{~b}$ and $\mathrm{c}$.

\section{Preparation of FITC labeled protein-based nanogel}

$0.5 \mathrm{mg}$ of FITC was dissolved in $0.5 \mathrm{~mL}$ of DMSO. Then the solution was added dropwise to $5.0 \mathrm{~mL}$ of BSA solution (in $\mathrm{pH}$ 8.5 BB solution, concentration of BSA was $0.5 \mathrm{mg} \mathrm{mL}^{-1}$ ) stirred for $8 \mathrm{~h}$ at $4{ }^{\circ} \mathrm{C}$ in a dark place. Subsequently the solution was dialyzed against $20 \mathrm{mM}$ PB solution ( $\mathrm{pH}$ 7.4) for $24 \mathrm{~h}$ (MWCO: $1000 \mathrm{Da}$ ) and fresh PB solution was exchanged every $6 \mathrm{~h}$. All FITC labeled BSA-based nanogels were obtained from modifications based on this FITC-labeled BSA to ensure the same amount of FITC in each sample.

\section{Preparation of Cy5.5 labeled protein-based nanogel}

$0.4 \mathrm{mg}$ of Cy5.5 was dissolved in $0.5 \mathrm{~mL}$ of DMSO. Then the solution was added dropwise to $5.0 \mathrm{~mL}$ of BSA solution (concentration of BSA was $0.5 \mathrm{mg} \mathrm{mL}^{-1}$ ) and stirred for $1 \mathrm{~h}$ at room temperature in a dark place. Subsequently the solution was dialyzed against $20 \mathrm{mM}$ PB solution ( $\mathrm{pH} 7.4$ ) for $12 \mathrm{~h}$ (MWCO: $1000 \mathrm{Da}$ ) and fresh PB solution was exchanged every $4 \mathrm{~h}$. To determine the content of Cy5.5 in the BSA solution, the solution was lyophilized and then redissolved in DMSO. The amount of Cy5.5 in the nanogel was determined by measuring the absorbance at $680 \mathrm{~nm}$ with a UV-Vis spectrophotometer. All the Cy5.5 labelled BSA-based nanogels were obtained from modifications based on this Cy5.5-labeled BSA to ensure the same amount of Cy5.5 in each sample.

\section{Characterizations}

Dynamic light scattering (DLS). Dynamic light scattering (DLS) was used to measure the size, size distribution and zeta potential of particles in aqueous solution and was carried out with a Malvern Zetasizer Nano S instrument (Malvern Instruments Ltd) equipped with a $4.0 \mathrm{~mW} \mathrm{He-Ne} \mathrm{laser} \mathrm{operating} \mathrm{at} \lambda$
$=633 \mathrm{~nm}$. All samples $\left(0.5 \mathrm{mg} \mathrm{mL}{ }^{-1}\right.$ of BSA $)$ were measured at a scattering angle of $90^{\circ}$ in $20 \mathrm{mM}$ phosphate buffer (PB) at room temperature $\left(25^{\circ} \mathrm{C}\right)$.

Transmission electron microscopy (TEM). Transmission electron microscopy (TEM) studies were performed with a Tecnai G2spirit Biotwin instrument at a voltage of $120 \mathrm{kV}$ (FEI, USA). Samples were prepared by drop-casting solutions onto carbon-coated copper grids, and then air-drying at room temperature. Then the samples were negatively stained by $1 \%$ phosphotungstic acid ( $\mathrm{pH}=7.0)$ before measurement.

${ }^{31} \mathrm{P}$ nuclear magnetic resonance spectroscopy (NMR). ${ }^{31} \mathrm{P}$ nuclear magnetic resonance spectroscopy (NMR) spectra were recorded using a Varian Mercury Plus $400 \mathrm{MHz}$ spectrometer to confirm the attachment of PMPC onto the nanoparticles. Samples were prepared by dissolving in $50 \% \mathrm{H}_{2} \mathrm{O} / 50 \% \mathrm{D}_{2} \mathrm{O}$ at $0.25 \mathrm{mg} \mathrm{mL}^{-1}$ and the $\mathrm{pH}$ was adjusted to 7.4 .

Flow cytometry (FCM). Flow cytometry (FCM) was assessed using a flow cytometer (Accuri C6, Becton, Dickinson and Company, Shanghai, China). TAT was labeled with FITC in $\mathrm{pH}$ $=8.5,20 \mathrm{mM}$ PB. Non-TAT modified (used as control to draw the gate) and FITC-labeled TAT-modified nanoparticles were recorded in a flow cytometer (100 000 nanoparticles studied) to confirm the attachment of TAT onto the system.

SDS-PAGE. SDS-PAGE gel electrophoresis was carried out to determine the molecular weight of the nanoparticles. Native BSA, nBSA, and three TAT-modified systems were used as samples and Protein Ladder (purchased from Beyotime, Shanghai, China) was used as the maker. Precast gel was purchased from Willget Biotech Co., Ltd, Shanghai, China. After staining and decolourization for three days, the results were shown in BIO-RAD Gel Doc XR+ (BIO-RAD, USA).

\section{Cell culture and animals}

L929 (mouse fibroblast cells), C6 (mouse glioma cells) were purchased from the Shanghai Institute for Biological Sciences, Chinese Academy of Sciences Institute of Cell Resource Center (Shanghai, China). L929 cells were cultured using a medium of DMEM-high glucose with $10 \%$ FBS and $1 \%$ penicillinstreptomycin. C6 cells were cultured in a medium of DMEM/ F12k (1:1) with 10\% FBS and 1\% penicillin-streptomycin. Rat brain-derived microvascular endothelial cells (RBMEC), astrocytes (RBAC) and pericytes (RBPC) and corresponding complete medium were all purchased from $\mathrm{CHI}$ Scientific, Inc., Jiangyin, China. Cells were cultured at $37{ }^{\circ} \mathrm{C}$ with $5 \% \mathrm{CO}_{2}$.

$\mathrm{KM}$ mice and BalB/C nude mice were purchased from Shanghai SLAC Laboratory Animal CO. LTD. (Shanghai, China). Animals were placed in a particular pathogen-free animal house with free access to food and water. All animal experiments were conducted in agreement with the guidelines of the Institutional Animal Care and Use Committee (IACUC) of Shanghai Jiao Tong University and the IACUC of Shanghai Jiao Tong University and were conducted in agreement with the guidelines of the Association for Assessment and Accreditation of Laboratory Animal Care (AAALAC). The animal experiments protocol was approved by the Animal Experimentation Ethics Committee at Shanghai Jiao Tong University School of Pharmacy. 


\section{In vitro cytotoxicity assay}

The cytotoxicity of the delivery system was assessed using MTT assay. L929 cells were plated in a 96-well plate at a cell density of $1.0 \times 10^{4}$ cells per well and incubated for $24 \mathrm{~h}$ at $37^{\circ} \mathrm{C}$ and $5 \%$ $\mathrm{CO}_{2}$ before they were treated with different concentrations of TBSA, nBSA and TAT-nBSA, respectively. All samples were incubated with the cells for $24 \mathrm{~h}$. Before the MTT assay, each well was refilled with fresh medium. For the MTT assay, 20.0 $\mu \mathrm{L}$ of $5.0 \mathrm{mg} \mathrm{mL}{ }^{-1}$ MTT (Beyotime Institute of Biotechnology, Shanghai, China) solution was added to each well and incubated for $4 \mathrm{~h}$ at $37^{\circ} \mathrm{C}$. After dissolving the formed fomazan with $150.0 \mu \mathrm{L}$ of DMSO in each well, the plates were shaken for $5 \mathrm{~min}$ with a shaker. The absorbance (OD value) was measured at $490 \mathrm{~nm}$ with a microplate reader. The cytotoxicity was measured by comparing it with the absorbance at each concentration and the control group.

\section{Cell internalization of delivery system}

The cell internalization assay was assessed using a flow cytometer (Accuri C6, Becton, Dickinson and Company, Shanghai, China). L929 and C6 cells were plated in 6-well plates at a cell density of $2 \times 10^{5}$ cells per well and incubated for $24 \mathrm{~h}$ at $37{ }^{\circ} \mathrm{C}$ and $5 \% \mathrm{CO}_{2}$ before they were treated with $62.5 \mu \mathrm{g} \mathrm{mL} \mathrm{m}^{-1}$ FITC-labeled TBAS, nBSA and TAT-nBSA, respectively. After treatment for $0.25,0.5,1,2$ and $3 \mathrm{~h}$, respectively, the cells were washed with PBS three times and digested with $0.05 \%$ trypsin EDTA (Gibco, Life Technologies, Shanghai, China). After configuration at $10^{4} \mathrm{rpm}$ for $5 \mathrm{~min}$, the cells were resuspended with $500.0 \mu \mathrm{L}$ of fresh medium (without FBS). The control group was analyzed first by flow cytometer to draw the gate and all the other tested groups were collected and recorded with a limit of $P_{1}=10 \mathrm{~K}$ in the gate. The fluorescence signal of the labeled FITC was collected in the first channel named FL1. All other groups were collected in the same way as the control group.

For in vitro imaging, C6 cells were seeded on 6-well plates at a density of $1 \times 10^{5}$ cells per well with a cover glass on the bottom. After $24 \mathrm{~h}, 62.5 \mu \mathrm{g} \mathrm{mL} \mathrm{mL}^{-1}$ FITC-labeled TBAS, nBSA and TAT-nBSA were incubated with cells for $0.25,0.5,1,1.5,2$ and $3 \mathrm{~h}$, respectively, at $37^{\circ} \mathrm{C}$. To remove the free conjugates, the cells were washed three times for 5 min with PBS and fixed in $3.7 \%$ formaldehyde solution $(1.0 \mathrm{~mL}$ per well) for $30 \mathrm{~min}$. The nuclear dye DAPI was used to stain the nuclei in the experiment. Images of cells were acquired using a Zeiss LSM 5 Pascal Confocal laser scanning microscope (Carl Zeiss AG, Oberkochen, Germany) imaging system.

\section{In vitro BBB model-based assay}

The in vitro $\mathrm{BBB}$ model was established using a primary coculture with RBMEC, RBAC and RBPC, as described by Deli et al. A collagen-coated $0.4 \mu \mathrm{m}$ PTFE membrane of the transwell inserts (12 well, Corning Life Sciences, MA, USA) was used. RBPC were seeded on the bottom side of the inserts at a density of $1.5 \times 10^{4}$ cells $\mathrm{cm}^{-2}$ and RBAC were seeded on the bottom of the plate at the same density on day 1 . The cells were allowed to undergo strong adhesion overnight. Then RBMEC were seeded on the upper side of the insert-chamber of the 12-well culture plates, and RBAC were seeded on the bottom of this culture plate, with a density of $1.5 \times 10^{5}$ cells $\mathrm{cm}^{-2}$ on day 0 . From day 1 , the BBB models were maintained in RBMEC medium, supplemented with $500.0 \mathrm{nM}$ hydrocortisone. The media was changed every other day and the in vitro BBB models were put into use from day 4 . When trans-epithelial electric resistance (TEER) reached $250.0 \Omega \mathrm{cm}^{2}$ by subtraction of the resistance of an insert without cells, this showed that the in vitro BBB model was ready for the permeability assay. TEER was recorded using an Autolab PGSTAT302N (Metrohm, Switzerland) electrochemical test system and calculated using equation (eqn (1)):

$$
\mathrm{TEER}=\left(\mathrm{TEER}_{\text {filter with cells }}-\mathrm{TEER}_{\text {filter without cells }}\right) \times A
$$

where $A$ is the area of the filter in $\mathrm{cm}^{2}$. The model was characterized by immunochemistry analysis and electron microscopy. After washing and fixation, RBMEC were incubated with antivon Willebrand factor rabbit polyclonal antibody, RBAC with anti-GFAP mouse monoclonal antibody, and RBPC with antialpha smooth muscle actin antibody (Abcam, Shanghai, China). All primary antibodies were used in $1: 100$ dilution. As secondary antibodies FITC conjugated goat anti-rabbit IgG (from CHI Scientific, Inc., Jiangyin, China) were used in a dilution 1 : 1000. A Zeiss LSM 5 Pascal confocal microscope (Carl Zeiss AG, Oberkochen, Germany) was used to examine the staining.

Cells grown on the membrane were fixed with $2.5 \%$ glutaraldehyde for $30 \mathrm{~min}$ at $4{ }^{\circ} \mathrm{C}$. After washing with $0.1 \mathrm{M}$ PBS three times, the membranes of the culture inserts with the cells on the two sides were removed from their support and placed into a 24-well chamber slide and were postfixed in $1 \% \mathrm{OsO}_{4}$ for $1 \mathrm{~h}$. Following washing with $0.1 \mathrm{M}$ PBS, the cells on the membrane were gradient dehydrated using ethanol, block-stained with resin in 99\% acetone $(1: 1)$ for $1 \mathrm{~h}$ and embedded in 100\% resin. A Leica UC6 ultramicrotome (Leica Microsystems, Milton Keynes, UK) was used to give ultrathin sections cut perpendicularly and a $120 \mathrm{kV}$ biology transmission electron microscope (Tecnai G2 spirit Biotwin, FEI, USA) was used to examine the ultrathin membranes.

For the permeability assay, $0.5 \mathrm{mg} \mathrm{mL}^{-1}$ FITC labeled TBSA, nBSA and TAT-nBSA were added to the upper chamber of the transwells to yield a final concentration of $62.5 \mu \mathrm{g} \mathrm{mL}{ }^{-1}$. At 20 , 40 and 60 min post-treatment, inserts were moved to new well where fresh PBS was contained. The concentrations of transported nanoparticles were measured by flow cytometry and analyzed using the standard curve method. Transport was expressed as microliters of donor (luminal) compartment volume from which the tracer was completely cleared. The permeability coefficients $\left(P_{\mathrm{e}}, \mathrm{cm} \mathrm{s}^{-1}\right)$ for the nanoparticles were calculated as previously described.,70 Cleared volume was calculated from the concentration $(C)$ of the nanoparticles in the basolateral side (BL) and apical side (AP) compartments and the volume $(V)$ of the BL compartment by the following equation (eqn (2)):

$$
\text { Cleared volume }(\mu \mathrm{L})=\left(C_{\mathrm{BL}} \times V_{\mathrm{BL}}\right) / C_{\mathrm{AP}}
$$


The average cleared volume was plotted versus time, and the permeability multiplied by the surface area product value for the endothelial monolayer $\left(\mathrm{PS}_{\mathrm{e}}\right)$ was calculated by the following formula (eqn (3)):

$$
1 / \mathrm{PS}_{\mathrm{e}}=1 / \mathrm{PS}_{\text {total }}-1 / \mathrm{PS}_{\text {insert }}
$$

$\mathrm{PS}_{\mathrm{e}}$ divided by the surface area generated the endothelial permeability coefficient $\left(P_{\mathrm{e}}\right.$, in $\left.10^{-6} \mathrm{~cm} \mathrm{~s}^{-1}\right)$.

\section{In vivo imaging studies}

Whole-body in vivo biodistribution and brain accumulation in healthy Balb/C nude mice was examined using an explore Optix MX animal optical molecular imaging system (General Electric Company, USA) at $580 \mathrm{~nm}$ excitation and $692 \mathrm{~nm}$ emission wavelengths. Each mouse was injected in the tail vein with 200.0 $\mu \mathrm{L}$ per mouse of Cy5.5 labeled $0.5 \mathrm{mg} \mathrm{mL}^{-1}$ TBSA, nBSA and TAT-nBSA, respectively. Then the mice were given general anesthesia with glutaraldehyde (2\%). At time points after injection of $0.5,1,2,3,4,5,6,24,48$ and $72 \mathrm{~h}$, the mice were fixed with tapes and pictures taken from the back.

\section{In vivo circulation time study}

The in vivo circulation times of TBSA, nBSA and TAT-nBSA nanoparticles were investigated in healthy $\mathrm{KM}$ mice $(\sim 40 \mathrm{~g})$. The FITC-labeled TBSA, nBSA and TAT-nBSA nanoparticles were injected into the tail vein intravenously at a dose of $3.0 \mathrm{mg}$ $\mathrm{kg}^{-1}$ (concentration of BSA) with three mice in each group. Time points selected for the nanoparticles were $0,2,6,10,24,48$, and $72 \mathrm{~h}$ post-injection. At each time point, mice were sacrificed and blood samples were collected in coagulating tubes to give serum. The samples were stored at $4{ }^{\circ} \mathrm{C}$ until analysis. The serum of each sample was analyzed using UV-Vis. The absorbance of each sample at $388 \mathrm{~nm}$ was recorded. The residual content in plasma at each time point was calculated as follows:

$$
\text { Residual content }(\%)=\mathrm{Abs}_{\text {time point }} / \mathrm{Abs}_{0 \mathrm{~h}} \times 100
$$

\section{Biodistribution in tissues}

Healthy 5-6 week male BalB/C mice, five mice for each group, were injected in the tail vein with $200.0 \mu \mathrm{L}$ per mouse of FITC labeled $0.5 \mathrm{mg} \mathrm{mL}^{-1}$ TBSA, nBSA and TAT-nBSA. Mice treated with the same amount of saline were used as a blank control. The mice for the biodistribution test were sacrificed by cervical dislocation after bloodletting from the retinal vein plexus $2 \mathrm{~h}$ and $24 \mathrm{~h}$ post-injection. The blood was collected in procoagulation tubes to get the serum. The brain tissues, hearts, livers, spleens, lungs and kidneys of each mouse were separated, weighed and washed three times with ice-cold PBS. The tissues were ultrasonically decomposed by an Ultrasonic Processor (Scientz-IID, Ningbo Scientz Biotechnology CO., LTD, Ningbo, China) at a concentration of $100.0 \mathrm{mg}$ weight tissue per milliliter of PBS. After centrifugation, the supernatant was collected and the fluorescence intensity (FI) of each sample was tested by a fluorescence spectrophotometer. The fluorescence intensity of each experimental sample was corrected by subtracting the fluorescence intensity value of the blank control. The final results were expressed as the percentage of FI of each tissue to the summary of all the organs of each mouse.

\section{Fluorescence microscopic examination of traversing the BBB}

5-6 week healthy male BalB/C mice, five mice for each group, were injected in the tail vein with $200.0 \mu \mathrm{L}$ per mouse of FITC labeled $0.5 \mathrm{mg} \mathrm{mL}^{-1}$ TBSA, nBSA and TAT-nBSA. The mice for the fluorescence intensity test were sacrificed by cervical dislocation at 1, 3, 9, 24, 48 and 72 h after i.p. injection, respectively. Brain tissues of each mouse were separated, weighed and washed once with PBS. The brains were ultrasonically decomposed at a concentration of $100.0 \mathrm{mg}$ weight tissue per milliliter of PBS. After centrifugation, the fluorescence intensity of each collected supernatant was tested by a fluorescence spectrophotometer.

To investigate nanoparticle accumulation inside the brain tissues, FITC-labeled nanoparticles $(200.0 \mu \mathrm{L}$ injection volume; $0.5 \mathrm{mg} \mathrm{mL} \mathrm{m}^{-1}$ nanoparticles in solution) were injected into the tail veins of 5-6 week healthy male BalB/C mice. 1, 2 and $24 \mathrm{~h}$ post treatment, the mice were sacrificed by cervical dislocation and their brains were separated and collected. The brain slices were taken by a freezing microtome section, $10 \mu \mathrm{m}$ in thickness, and every 20th slice was kept (Cryotome E, Thermo Fisher Scientific, USA). The air-dried samples were imaged using a Zeiss LSM 5 Pascal Confocal laser scanning microscope (Carl Zeiss AG, Oberkochen, Germany). Pictures were taken from the lower left part of each slice (Ex./Em. $=488 / 518 \mathrm{~nm})$.

To further confirm the intracerebral location of the nanoparticles and the relationship with the blood vessels, FITClabeled nanoparticles $(200.0 \mu \mathrm{L}$ injection volume; $0.5 \mathrm{mg}$ $\mathrm{mL}^{-1}$ nanoparticles in solution) were injected into the tail vein of 5-6 week healthy male BalB/C mice, 2 in each group. $2 \mathrm{~h}$ post treatment, the mice were sacrificed by cervical dislocation and their brains were separated and immersed in $4 \%$ paraformaldehyde overnight. The brain tissues were washed with PBS 3 times, each for $30 \mathrm{~min}$, and immersed in $20 \%$ sucrose solution overnight and kept at $4{ }^{\circ} \mathrm{C}$. The brain slices were taken by a freezing microtome section, $10.0 \mu \mathrm{m}$ in thickness, and every 20th slice was kept (Cryotome E, Thermo Fisher Scientific, USA). The air-dried slices were fixed with cold acetone for $10 \mathrm{~min}$ and washed with PBS 3 times, 5 min each time. EDTA antigen repair buffer $(\mathrm{pH}=8.0)$ was used to repair the slices within a microwave for $10 \mathrm{~min}$. After air-drying, the slices were washed with PBS 3 times, 5 min each time. After blocking with $3 \% \mathrm{BSA}$ in PBS for $30 \mathrm{~min}$ at room temperature, the slices were incubated with an antibody against PECAM-1 (CD31) (BD Biosciences) overnight at $4{ }^{\circ} \mathrm{C}$. Cy-3 conjugated secondary antibody (Invitrogen Carlsbad, CA) was applied for $1 \mathrm{~h}$ at room temperature, together with DAPI. Samples were analyzed with a fluorescence microscope (Nikon Eclipse TI-SR, Japan).

\section{Statistical analysis}

The results were analyzed using Tukey's honest significant difference test for multiple comparisons followed by John Wilder Tukey's test to identify significant differences between 
groups. The family-wise significance and confidence level was $p$ $<0.05$. All results were expressed as means \pm standard error of mean (SEM).

\section{Results and discussion}

In this study, core-shell protein-based nanocarriers with long circulation ability (Fig. 1) have been developed via three typical steps according to our previous procedures. ${ }^{68,69}$ Bovine serum albumin (BSA) was chosen as the single-sized model protein core to guarantee an ultra-small size and a uniform size distribution of the nanoparticles. Then the PMPC shell could ensure a long delivery system lifetime in vivo and a biomembrane-like structure. The existence of a PMPC outer layer on the surface of MPC-modified BSA (nBSA) was confirmed by ${ }^{31} \mathrm{P}$ nuclear magnetic resonance spectroscopy $\left({ }^{31} \mathrm{P} \mathrm{NMR}\right)$. As shown in Fig. 2a, the clean peak of MPC is at $0.57 \mathrm{ppm}$ and native BSA shows no signal. The spectrum of nBSA shows peaks at $0.40 \mathrm{ppm}$, which represent the successful attachment of MPC onto the BSA surface. Meanwhile, to provide carboxyl groups for the conjugation of TAT, acrylic acid (AA) was introduced. As shown in Fig. 2f, the zeta potential of nBSA is $-4.49 \mathrm{mV}$. After the introduction of $\mathrm{AA}$, this decreases to $-9.55 \mathrm{mV}$ in acrylic nBSA. With the conjugation of TAT peptide onto the surface, the transport ability as well as the concentration and retention time of the nanoparticles inside brain will be extremely improved. To confirm the attachment of TAT peptides on the surface of the delivery platform (TAT-nBSA), TAT was labeled with FITC and

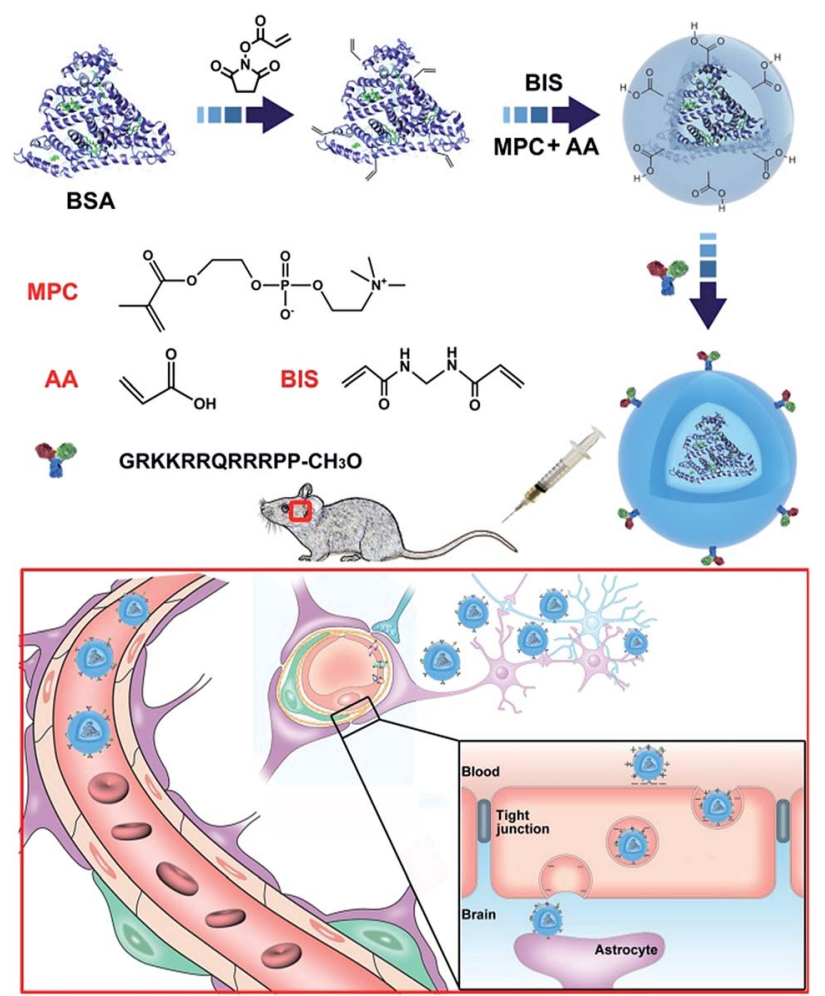

Fig. 1 Synthesis of the TAT-nBSA nanoparticles with zwitterionic polymer encapsulation for prolonged retention in the brain. the fluorescence signal of the nanoparticles was collected and analyzed. Compared with non-TAT-modified nBSA (Fig. 2b), TAT-modified TAT-nBSA nanoparticles show an extra FITC fluorescence signal (Fig. 2c), from which the attachment of TAT peptides on the surface of the delivery system can be confirmed.

With different amounts of TAT conjugated on the surface, a series of nanoparticles were obtained (TAT-1-nBSA, TAT-5nBSA and TAT-10-nBSA, where the number stands for the molar ratio of TAT to BSA). The molecular weight (MW) of the resulting delivery platforms was characterized by SDS-PAGE (Fig. 2d). Native BSA shows an MW around $65 \mathrm{kD}$. After surface modification, the MW of nBSA and TAT-nBSA increases to around $120 \mathrm{kD}$. With several modification steps, the particle size and surface property were also changed. With the help of dynamic light scattering (DLS) and a transmission electron microscope (TEM), the size and morphology parameters of the BSA-based nanoparticles were recorded (Fig. S1 $\dagger$ ). As shown in Fig. 2e and f, TBSA, nBSA, acrylic nBSA and TAT-nBSA show differences in size but are similar in zeta potential, close to electrical neutrality. The sizes of the nanoparticles increase from $5.24 \mathrm{~nm}$ to around $22.00 \mathrm{~nm}$ after modification, and the zeta potentials of TAT-nBSA are around $-7 \mathrm{mV}$ (Table 1 ). The TEM images in Fig. 2g-i show that TBSA, nBSA and TAT-1-nBSA exhibit uniform spherical nanoparticles and well-defined size distributions, which correspond to the results of DLS observation very well. No significant morphological changes can be observed after the surface modifications, as evidenced by TEM imaging.

The biocompatibility of the materials is important for the delivery system. Here we used MTT to examine the cytotoxicity of the nanoparticles. As shown in Fig. S2a, $\uparrow$ after the incubation of L929 cells with TBSA, nBSA, TAT-1-nBSA, TAT-5-nBSA and TAT-10-nBSA for $24 \mathrm{~h}$, over $80 \%$ of the cells can survive even after co-incubation with an extremely high concentration (125.0 $\left.\mu \mathrm{g} \mathrm{mL} \mathrm{m}^{-1}\right)$. The MTT assays confirm the low in vitro cytotoxicity of these nanoparticles.

The cell internalization ability of the delivery platform is the basis of in vivo BBB crossing efficacy. Herein we first tested the cell internalization ability with monolayer cells. As observed by confocal microscopy (Fig. S2b $\dagger$ ), after $3 \mathrm{~h}$ of incubation, a small amount of non-TAT-modified nanoparticles is observed in C6 cells and localized in the cytoplasm. In contrast, TAT-modified nanoparticles (TBS, TAT-1-nBSA, TAT-5-nBSA and TAT-10-nBSA) can largely enter C6 cells. Among these four TAT-modified groups, the TAT-10-nBSA group shows the greatest permeability. To further demonstrate the extra cell penetrating ability of TAT-modified nanoparticles, quantitative results of flow cytometric analysis were collected (Fig. S2c and d†). With the increase in incubation time, the amount of TAT-modified nanoparticles internalized increases in both L929 and C6 cell lines. During the observed $3 \mathrm{~h}$, the total amount of nanoparticles that penetrate the cell membranes is much higher for the TAT-modified groups than for the non-modified group both in L929 cells and C6 cells. In particular, for the TAT-10-nBSA group, $28.2 \%$ of all the nanoparticles can go into the L929 cells and $65.2 \%$ into the C6 cells, while the numbers for the TBSA group are $10.3 \%$ and $24.3 \%$, for TAT-1-nBSA group they 
Gate: (P1 in all)

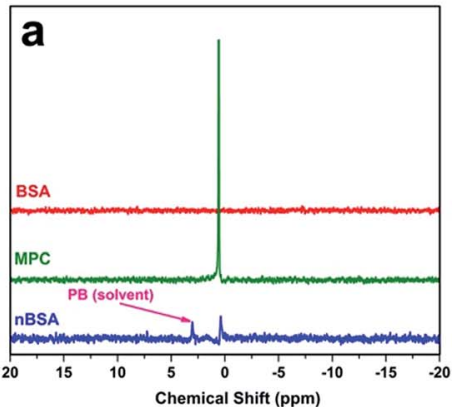

b 签

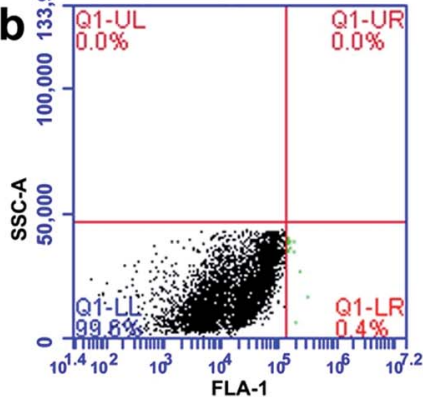

\% Gate: (P1 in all)

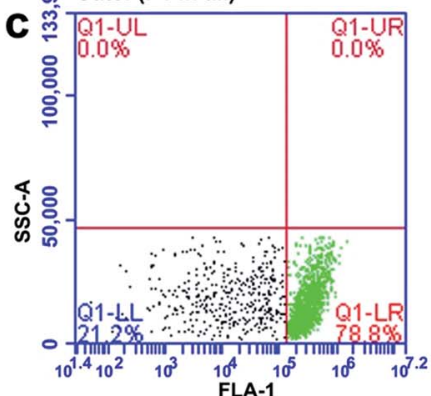

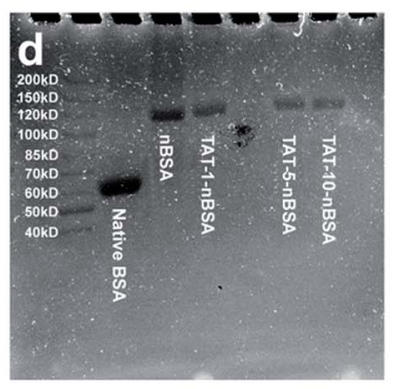
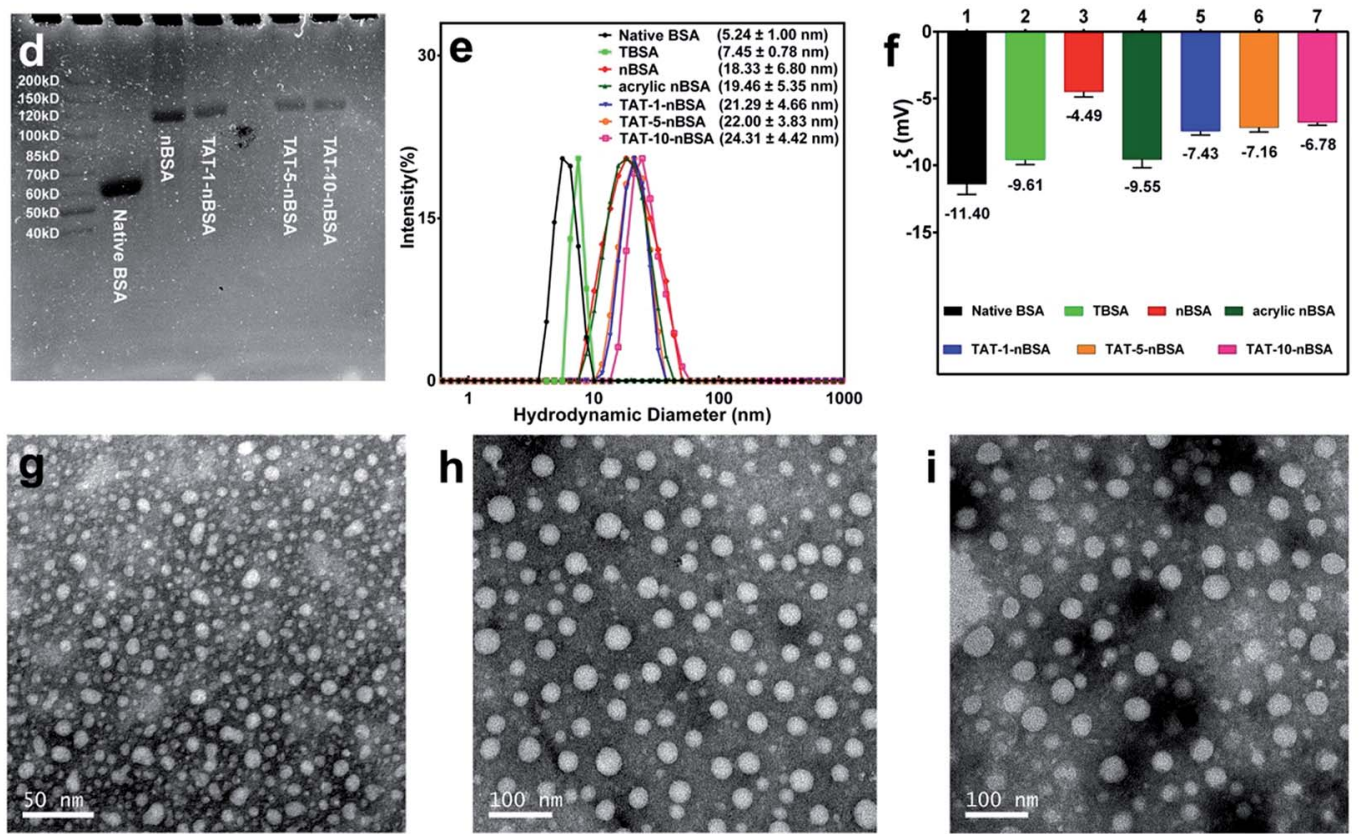

Fig. 2 Characterization of BBB-crossing delivery system. (a) ${ }^{31} \mathrm{P}$ NMR of phosphate buffer (PB, 20 mM, pH 7.4), MPC monomer, nBSA nanoparticles $\left(0.5 \mathrm{mg} \mathrm{mL}^{-1}\right.$ in $\left.\mathrm{PB}\right), \mathrm{BSA}\left(0.5 \mathrm{mg} \mathrm{mL}^{-1}\right.$ in PB) in $50 \% \mathrm{H}_{2} \mathrm{O} / 50 \% \mathrm{D}_{2} \mathrm{O}$. Flow cytometry of the nanoparticles, signal of FITC was collected from FL1 channel, 100000 particles were recorded and analyzed (b, c). Acrylic nBSA (b), and FITC-labeled TAT-nBSA (c). (d) SDS-PAGE of native BSA, nBSA, TAT-1-nBSA, TAT-5-nBSA and TAT-10-nBSA nanoparticles. (e) The hydrodynamic sizes of native BSA, TBSA, nBSA, acrylic nBSA, TAT1-nBSA, TAT-5-nBSA and TAT-10-nBSA nanoparticles. (f) Zeta potential of native BSA, TBSA, nBSA, acrylic nBSA, TAT-1-nBSA, TAT-5-nBSA and TAT-10-nBSA nanoparticles. The TEM images TBSA (g), nBSA (h), and TAT-1-nBSA (i) nanoparticles.

Table 1 All nanoparticles prepared, their composition and DLS parameters ${ }^{a}$

\begin{tabular}{llllllll}
\hline Systems & MPC & AA & TAT & TAT/BSA (n/n) & d (nm) & $\xi(\mathrm{mV})$ & MW (kD) \\
\hline Native BSA & No & No & No & 0 & $5.24 \pm 1.00$ & -11.40 \\
TBSA & No & No & Yes & $5 / 1$ & $7.45 \pm 0.78$ & -9.61 \\
nBSA & Yes & No & No & 0 & $18.33 \pm 6.80$ & -4.49 \\
Acrylic nBSA & Yes & Yes & No & 0 & $19.46 \pm 5.35$ & -9.55 \\
TAT-1-nBSA & Yes & Yes & Yes & $1 / 1$ & $21.29 \pm 4.66$ & -7.43 \\
TAT-5-nBSA & Yes & Yes & Yes & $5 / 1$ & $22.00 \pm 3.83$ & -7.16 \\
TAT-10-nBSA & Yes & Yes & Yes & $10 / 1$ & $24.31 \pm 4.42$ & -6.78
\end{tabular}

${ }^{a}$ Diameters $(d)$ and zeta potentials $(\xi)$ were all measured by dynamic light scattering (DLS). The dispersed phase is $20 \mathrm{mM}$ phosphate buffer, pH $=$ 7.4. MW stands for molecular weight obtained from SDS-PAGE.

are $2.7 \%$ and $13.8 \%$, and for TAT-5-nBSA group they are $10.7 \%$ and $29.2 \%$, respectively. In contrast, for non-modified group nBSA nanoparticles, there are only $0.7 \%$ and $0.6 \%$ nanoparticles internalized by the cells. In summary, the conjugation of TAT peptide on the surface of nanoparticles can significantly improve cell internalization ability. The enhanced cell uptake of TAT-modified nanoparticles is beneficial for improving the potential drug delivery efficiency. Besides, for fibroblast cells 
and glioma cells in our study, the delivery system shows a propensity for much more internalization by the glioma cells no matter in which TBSA, TAT-1-nBSA, TAT-5-nBSA or TAT-10nBSA group, and this might be a hint for targeting delivery in vivo.

To further demonstrate the cell transport ability in a model much more similar to the real $\mathrm{BBB}$ in vivo than the monolayer cell lines, we constructed an in vitro BBB model to test the permeability efficacy of the delivery platforms. The set-up of the BBB model is shown in Fig. 3a, as previously described by Deli and co-workers. ${ }^{70}$ Rat brain microvascular endothelial cells (RBMEC) grew into a non-overlapping continuous monolayer film, showing close connections with each other, small size, and positive staining for von Willebrand factor (Fig. 3c). Rat brain astrocyte cells (RBAC) give positive immunostaining for GFAP, resembling astrocytic endfeet with a distinct morphology (Fig. 3b). Rat brain pericyte cells (RBPC) are different from RBMEC and RBAC both in morphology and size and have a large spread with irregular projections, and they are positive for alpha-smooth muscle actin immunostaining (Fig. 3d). From the TEM images (Fig. 3e) it can be clearly observed that with the existence of both RBAC and RBPC, RBMEC grow on the membrane of the transwell with TJs and kissing points (white arrows in Fig. 3e).

The integrity of the RBMEC monolayer in the in vitro BBB model was monitored by the trans epithelial electric resistance (TEER) value during the experiments, which was typically above $250.0 \Omega \mathrm{cm}^{2}$. The permeability coefficients $P_{\mathrm{e}}$ of the different groups are collected in Table 2 . This reveals that TAT-5-nBSA possesses the most prominent transport capability with an endothelial permeability coefficient $P_{\mathrm{e}}$ of $17.703 \times 10^{-6} \mathrm{~cm} \mathrm{~s}^{-1}$ compared to other groups. $4.09 \%$ of initial TBSA, $3.93 \%$ of initial TAT-1-nBSA, $4.29 \%$ of initial TAT-5-nBSA and $2.43 \%$ of initial TAT-10-nBSA nanoparticles are found in BL after $60 \mathrm{~min}$ of incubation, but only $0.75 \%$ of non-TAT-modified nBSA could be detected under the same conditions. In addition to the

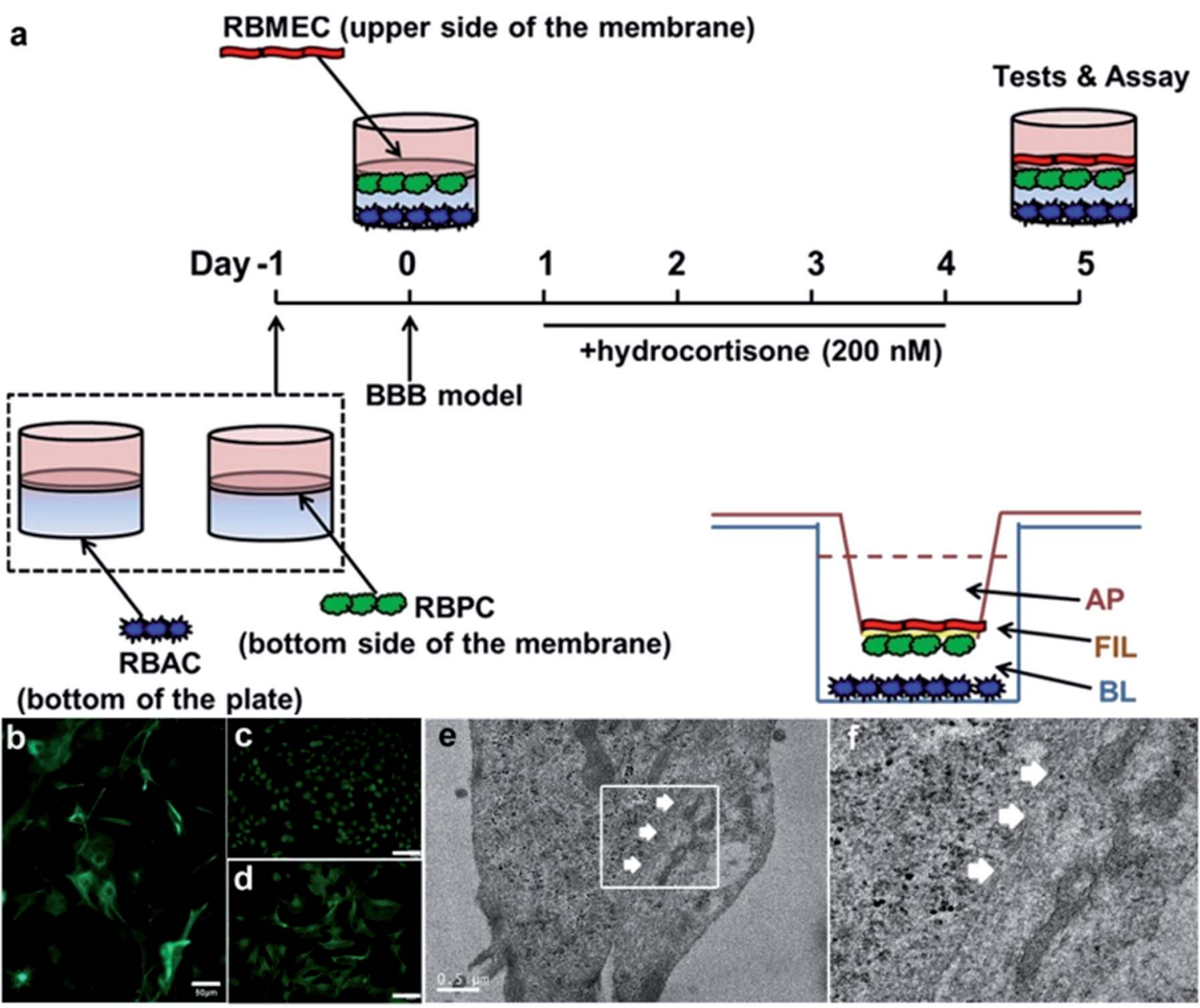

Fig. 3 In vitro BBB study. (a) Schematic drawing of the preparation of the in vitro BBB model. On day 0, RBMEC was added to the luminal compartment of the inserts with RBPC on the bottom side of the inserts and RBAC on the bottom of the 12-well plates. From day 1, cells were grown with $500 \mathrm{nM}$ hydrocortisone in the medium. Experiments were performed on day 4. (b-d) Characterization of primary cells by immunofluorescence microscopy. RBAC was positive for glial fibrillary acidic protein (GFAP, Fig. 3b), RBMEC was positive for factor VIII-related antigen/von Willebrand factor (Fig. 3c), and RBPC gave a positive immunostaining for alpha smooth muscle actin (Fig. 3d). Scale bar was $100 \mu \mathrm{m}$ for Fig. $3 c$ and d. (e) TEM image of RBMEC grown on the upper side of the inserts. (f) Magnified version of white box part in (e). White arrows were the kissing points (part of tight junctions). 
Table 2 Permeability of the four different delivery systems across the in vitro BBB model

\begin{tabular}{|c|c|c|c|c|}
\hline Systems & $P_{\mathrm{e}}\left(10^{-6} \mathrm{~cm} \mathrm{~s}^{-1}\right)^{a}$ & $R^{2 b}$ & $\begin{array}{l}\text { Transport in } \\
\text { BL }(\%, 60 \mathrm{~min})\end{array}$ & $\begin{array}{l}\text { Uptake in FIL } \\
(\%, 60 \mathrm{~min})\end{array}$ \\
\hline TBSA & 11.695 & 0.9911 & 4.09 & 43.18 \\
\hline TAT-1-nBSA & 9.585 & 0.9993 & 3.93 & 42.50 \\
\hline TAT-5-nBSA & 17.703 & 0.9897 & 4.29 & 55.81 \\
\hline TAT-10-nBSA & 7.822 & 0.9895 & 2.43 & 38.99 \\
\hline
\end{tabular}

${ }^{a} P_{\mathrm{e}}$ : endothelial permeability coefficient for each system. ${ }^{b} R^{2}$ : goodness of fit for each system at three time points.

enhancement in transport ratio over the BBB, the TAT-modified delivery systems show an enhanced affinity with the cells (Fig. S3, $\uparrow$ RBMEC cellular monolayer (FIL)). After $60 \mathrm{~min}$ of incubation, about $55.81 \%$ of the total dosed TAT-modified nanoparticles (TAT-5-nBSA) remain inside the cells, 60 times as high as that of nBSA nanoparticles $(0.91 \%)$. This indicates that TAT peptides have played a specific role in mediating the BBB-penetration of the nanoparticles. In addition, comparing these four TAT-modified groups, TAT-5-nBSA nanoparticles possess the strongest ability both in crossing the in vitro $\mathrm{BBB}$ model and in contacting the RBMEC monolayers. As shown in Fig. S3, $\dagger$ as the number of modified TAT peptides increases from 5 to 10 for different TAT-modified groups, fewer particles are internalized by the RBMEC monolayer or transported from the apical side (AP) to the basolateral side (BL) during the observed 60 min. However, more TAT-10-nBSA nanoparticles appear in AP than TAT-5-nBSA nanoparticles. Unlike the results in monolayer cell line conditions, because of the existence of $\mathrm{BBB}$ in the in vitro $\mathrm{BBB}$ model, TAT shows both the penetration ability and the recognition effects of P-glycoproteins. Then the final permeation efficacy is the competition of these two opposite abilities. We suppose that excess TAT peptides (10 times BSA in molar ratio in our case) will give rise to more easy recognition of the delivery system by the BBB rather than better transport efficiency. Thus we could draw a conclusion that the BBB-crossing permeability is proportional to the amount of TAT peptides on the surface within a certain range. Beyond that, this efficacy would decline as the number of TAT increases. No big difference can be seen between the TBSA and TAT-5-nBSA groups. However, in this in vitro $\mathrm{BBB}$ model, the total amounts of nanoparticles in each group at the beginning and end of the whole test are equal to each other, and they will not be metabolized or cleared as happens in the real animal. Under such conditions, the non-fouling shell made no difference.
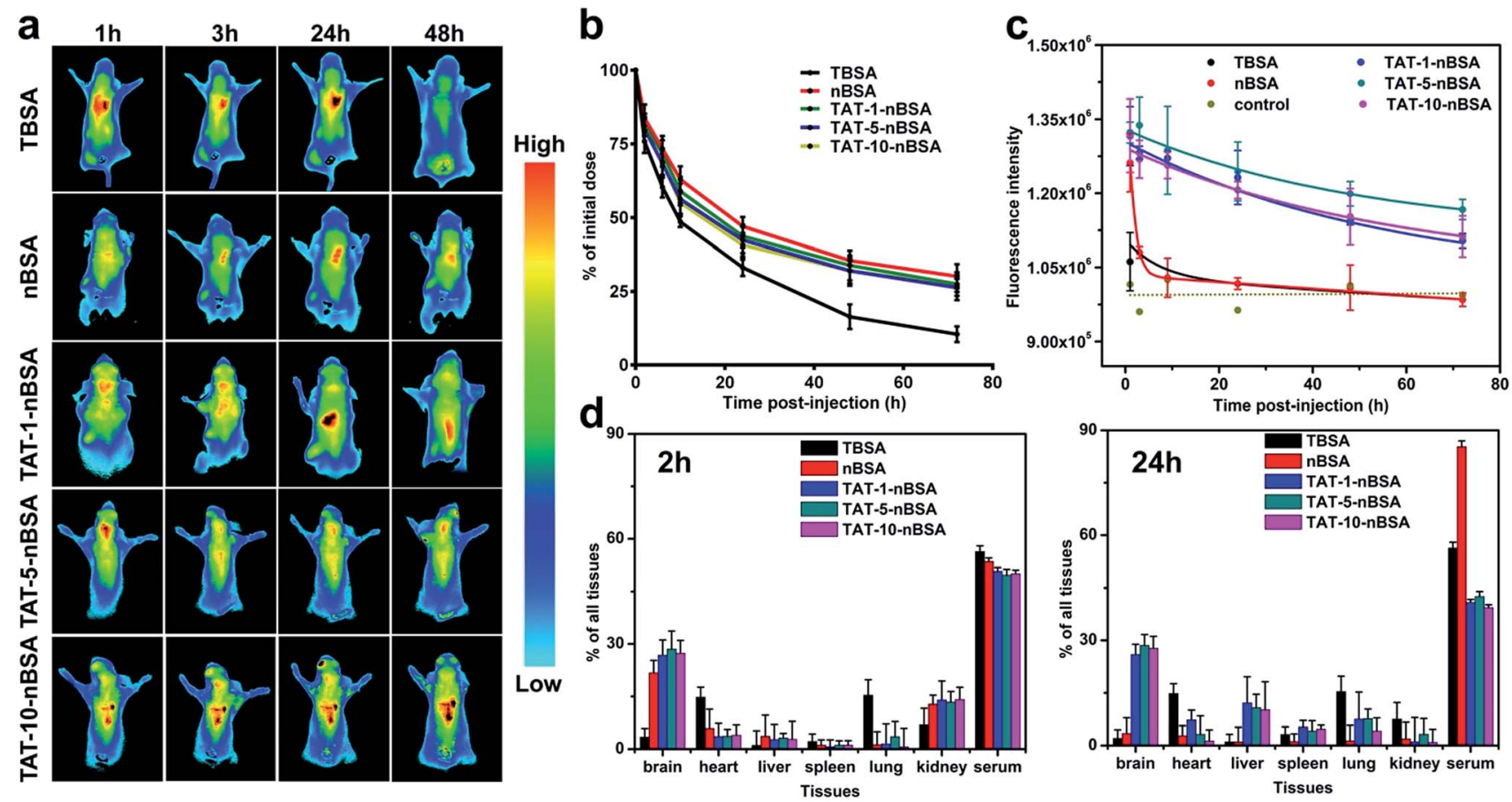

Fig. 4 In vivo study of the delivery system. (a) In vivo imaging of mice injected with Cy5.5-labeled TAT-modified and non-TAT-modified nanoparticles, post-injection for $1 \mathrm{~h}, 3 \mathrm{~h}, 24 \mathrm{~h}$ and $48 \mathrm{~h}$. (b) In vivo circulation time of FITC-labeled TBSA, nBSA and TAT-nBSA from $1 \mathrm{~h}$ to $72 \mathrm{~h}$ post-injection. (c) Intracerebral fluorescence of TBSA, nBSA and TAT-nBSA from $1 \mathrm{~h}$ to $72 \mathrm{~h}$ post-injection. (d) $2 \mathrm{~h}$ and $24 \mathrm{~h}$ post-injection biodistribution in brain, serum, heart, liver, spleen, lung and kidney. 
In order to show the real BBB-transport ability of the delivery systems, healthy nude mice were used for animal imaging. Firstly, through pharmacokinetic study, we can evaluate the circulation behavior of each group in vivo. As revealed in Fig. 4b, after encapsulation of zwitterionic polymer PMPC on the surface, the in vivo lifetime of nBSA and TAT-nBSA groups can be more than $72 \mathrm{~h}$, and their half-lifetimes were prolonged to about $24 \mathrm{~h}$. In contrast, due to the lack of this non-fouling shell, TBSA showed short circulation time and will be quickly cleared from the blood with a half-lifetime of around $10 \mathrm{~h}$. Based on this situation and difference, their BBB-permeability will be quite different from the in vitro BBB model-based test which takes no metabolism into consideration. As shown in Fig. 4a, $1 \mathrm{~h}$ after intravenous injection, a strong near-infrared (NIR) fluorescence signal shows up in the cerebral area and heart for both nonTAT-modified-nBSA and TAT-modified-nBSA groups. In contrast, non-PMPC-modified nanoparticles mainly located in lungs and kidneys due to their ultra-small size. $3 \mathrm{~h}$ after injection, the signal in the brain becomes much weaker in the nBSA group, while the signal remains strong in this area for TATnBSA nanoparticles. Even after 24 and $48 \mathrm{~h}$, the fluorescence signals of these three TAT-modified-nBSA groups remain strong in the brain and heart. However, weak signals continue to be present in the cerebral area of the control group treated with nBSA during the same time window. Conversely, due to its relatively short in vivo lifetime, TBSA was quickly cleared from the kidney and hence did not have much chance to contact with and penetrate through the $\mathrm{BBB}$. Compared to the results in cell line conditions and the in vitro $\mathrm{BBB}$ model case, we can clearly see the difference between the TBSA and TAT-5-nBSA groups in BBB permeability. We propose that this difference mainly comes from their in vivo circulation time, which can be obviously changed by the modification of the zwitterionic polymer shell on the surface. These in vivo results strongly demonstrate the critical role of long circulation in crossing the BBB of the delivery platform.

In addition, to better understand the biodistribution and accumulation of the nanoparticles, major organs including brain, heart, liver, spleen, lung, kidney and serum were collected and analyzed $2 \mathrm{~h}$ and $24 \mathrm{~h}$ after injection. As shown in Fig. $4 \mathrm{~d}$ and $\mathrm{S} 3, \dagger$ for TBSA nanoparticle treated mice, $2 \mathrm{~h}$ postinjection, the fluorescence signals are distributed extensively in serum (53.32\%) lung (15.35\%) and heart (14.79\%), and less in the liver $(1.09 \%)$. And a similar biodistribution can be observed for the TBAS group $24 \mathrm{~h}$ post-injection. And it was mainly cleared through the kidney. In the case of nBSA nanoparticle treated mice, $2 \mathrm{~h}$ post-injection, the fluorescence signals were distributed extensively in serum $(53.56 \%)$ and brain $(21.72 \%)$, and less in the liver $(3.65 \%)$. Nevertheless, after $24 \mathrm{~h}$, the nanoparticles nearly completely disappear from the brain $(3.43 \%)$. In contrast, for TAT-modified-nBSA nanoparticles, there are still $25.94 \%, 28.58 \%$ and $27.75 \%$,

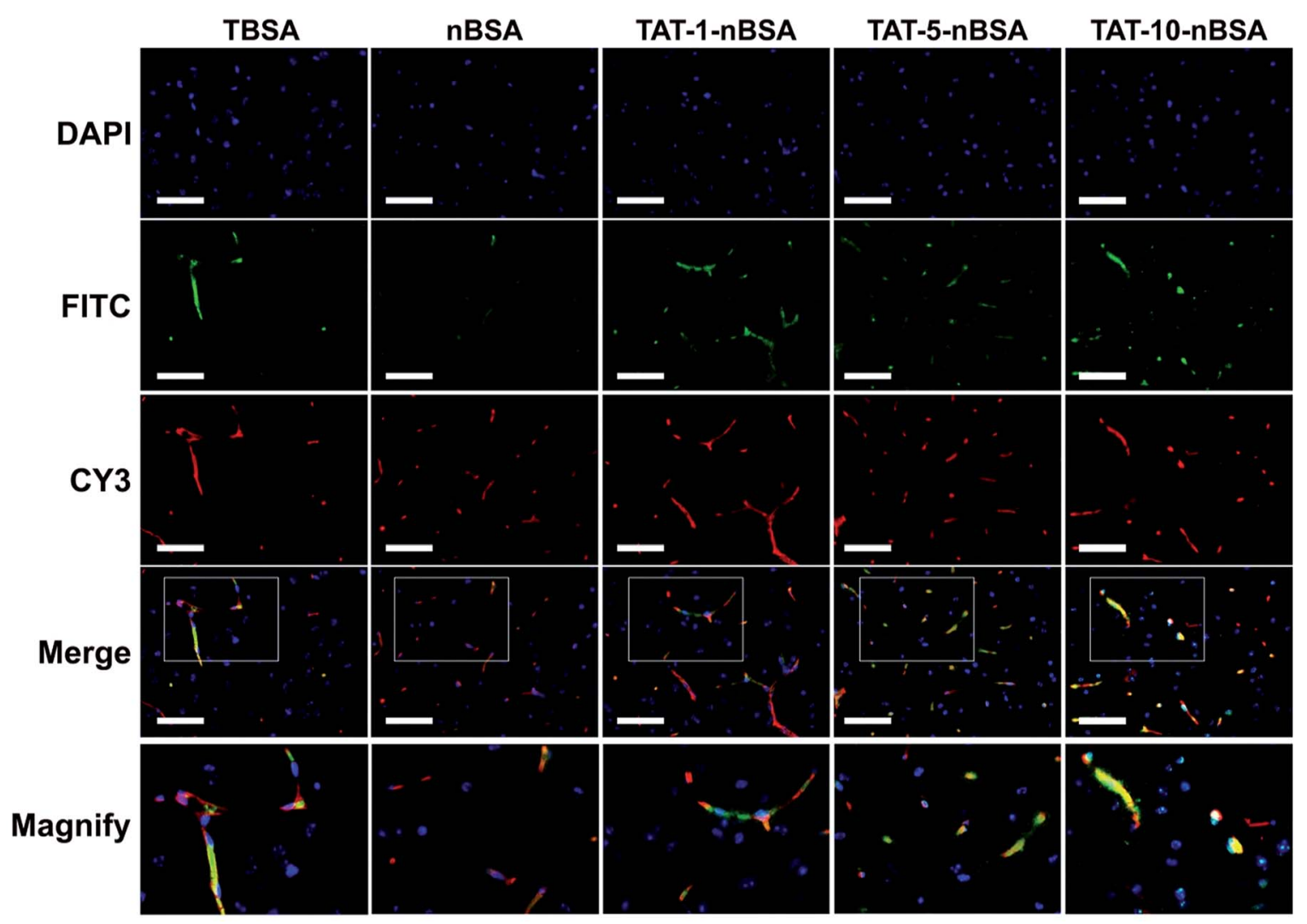

Fig. 5 Immunofluorescence image of mouse brain sections $(10 \mu \mathrm{m})$ from animals injected with FITC-labeled TBSA, nBSA, TAT-nBSA $2 \mathrm{~h}$ postinjection of the mice, respectively. Blue is the nucleus, red is the blood vessels and green is the nanoparticles. The last row is the magnified version of the white box in merge. Scale bar $=50 \mu \mathrm{m}$. 
respectively, in the brain even $24 \mathrm{~h}$ after treatment. The ability of these three groups of nanoparticles to go into the brain is much stronger than for the non-TAT-modified nBSA and nonzwitterionic polymer-modified TBAS. nBSA nanoparticles could go across the BBB in the first $2 \mathrm{~h}$ after injection maybe because of the existence of gaps in the BBB and their similar structure to the head-group of PC lipids in the outer membrane of living cells. Though the nBSA nanocarriers have a biomembrane-like structure, they would soon be expelled from the brain section due to the P-glycoproteins efflux pump on the BBB.

To make a further precise quantitative examination of the BBB-crossing ability of the nanoparticles, we used fluorescence examination by fluorescence spectrophotometer and imaging. As shown in Fig. 4b, the intracerebral retention time of the TATnBSA delivery systems is as long as $72 \mathrm{~h}$ according to the time window of the investigation period after single intravenous injection. In contrast, though conjugated with TAT, the TBSA group cannot effectively penetrate through the BBB due to its short lifetime in vivo. The results (Fig. S5†) show that TATmodification gives extra permeability of the BBB to the nanoparticles when compared with the non-TAT-labeled nBSA group. No matter whether $1 \mathrm{~h}, 2 \mathrm{~h}$ or $24 \mathrm{~h}$ post-injection, those nanoparticles could continue being seen inside the brain. In contrast, although nBSA nanoparticles could accumulate in the brain 1 and $2 \mathrm{~h}$ after injection, they could not remain there later and could barely be seen $24 \mathrm{~h}$ post-injection. Moreover, the TAT5-nBSA group shows a stronger ability to light the brain section than TBAS, TAT-1-nBSA and TAT-10-nBSA. As shown in Fig. 5, $2 \mathrm{~h}$ after tail vein injection, TAT-nBSA nanoparticles locate not only in the brain vascular endothelial cells but also in the brain parenchyma. However, for TBSA nanoparticles, though they can be largely internalized by brain vascular endothelial cells, due to their relatively short circulation time, hardly any can be observed in brain parenchyma. Comparing the results in Fig. 4c and $\mathrm{S} 4, \uparrow$ the TBSA and nBSA groups show the worst ability to go across the BBB from the blood circulation.

\section{Conclusions}

In conclusion, the aim of this work is to verify if long circulation lifetime is a critical issue for nanocarriers to deliver biologically active substances through the BBB, which could develop new effective strategies for drug delivery into the brain. In this regard, we have successfully fabricated an albumin-based nanoparticle delivery platform TAT-nBSA with distinct sizes for BBB-crossing. TAT-nBSA could simultaneously serve as a long lifetime circulating vehicle and an effective BBB-crossing agent. The TAT-nBSA nanoparticles are not recognized by the multidrug efflux system and remain inside the brain even up to $72 \mathrm{~h}$ with a high ratio of nearly $30 \%$ to the initial dose. Thus, this delivery system would be a suitable candidate as a BBB nanocarrier in clinical practice, whether for chronic or acute treatment. Moreover, BSA used in this system is just a model protein, which could be replaced by any type of active protein such as catalase, transferrin or even antibiotics for various additional functions to assist different types of drugs to bind onto the proteins for various kinds of CNS-related diseases. We believe this potential BBB-crossing platform could act as a meaningful addition to satisfy the unmet clinical need for various types of CNS disorders.

\section{Conflict of interest}

The authors declare no competing financial interest.

\section{Acknowledgements}

This work was financially supported by the National Basic Research Program of China (2015CB931801) and National Natural Science Foundation of China (51690151, 91527304, 51473093).

\section{References}

1 I. U. Ali and X. Chen, ACS Nano, 2015, 9, 9470.

2 S. Wohlfart, S. Gelperina and J. Kreuter, J. Controlled Release, 2012, 161, 264.

3 P. Arranz-Gibert, B. Guixer, M. Malakoutikhah, M. Muttenthaler, F. Guzman, M. Teixido and E. Giralt, J. Am. Chem. Soc., 2015, 137, 7357.

4 R. Prades, B. Oller-Salvia, S. M. Schwarzmaier, J. Selva, M. Moros, M. Balbi, V. Grazu, J. M. de La Fuente, G. Egea, N. Plesnila, M. Teixido and E. Giralt, Angew. Chem., Int. Ed., 2015, 54, 3967.

5 J. V. Georgieva, R. P. Brinkhuis, K. Stojanov, C. A. Weijers, H. Zuilhof, F. P. Rutjes, D. Hoekstra, J. C. van Hest and I. S. Zuhorn, Angew. Chem., Int. Ed., 2012, 51, 8339.

6 M. Malakoutikhah, M. Teixido and E. Giralt, Angew. Chem., Int. Ed., 2011, 50, 7998.

7 M. E. Brewster, W. R. Anderson, A. I. Webb, L. M. Pablo, D. Meinsma, D. Moreno, H. Derendorf, N. Bodor and E. Pop, Antimicrob. Agents Chemother., 1997, 41, 122.

8 V. Carelli, F. Liberatore, L. Scipione, M. Impicciatore, E. Barocelli, M. Cardellini and G. Giorgioni, J. Controlled Release, 1996, 42, 209.

9 S. Manfredini, B. Pavan, S. Vertuani, M. Scaglianti, D. Compagnone, C. Biondi, A. Scatturin, S. Tanganelli, L. Ferraro and P. Prasad, J. Med. Chem., 2002, 45, 559.

10 M. Gynther, K. Laine, J. Ropponen, J. Leppänen, A. Mannila, T. Nevalainen, J. Savolainen, T. Järvinen and J. Rautio, J. Med. Chem., 2008, 51, 932.

11 M. Gynther, J. Ropponen, K. Laine, J. Leppänen, P. Haapakoski, L. Peura, T. Järvinen and J. Rautio, J. Med. Chem., 2009, 52, 3348.

12 R. J. Boado, Q.-H. Zhou, J. Z. Lu, E. K.-W. Hui and W. M. Pardridge, Mol. Pharmaceutics, 2009, 7, 237.

13 R. J. Boado, Y. Zhang, Y. Zhang, C. F. Xia, Y. Wang and W. M. Pardridge, Biotechnol. Bioeng., 2008, 99, 475.

14 R. J. Boado, Y. Zhang, Y. Zhang, C.-F. Xia and W. M. Pardridge, Bioconjugate Chem., 2007, 18, 447.

15 R. J. Boado, E. K. Hui, J. Z. Lu, R. K. Sumbria and W. M. Pardridge, Bioconjugate Chem., 2013, 24, 1741. 
16 Y. L. Xie, W. Lu and X. G. Jiang, Behav. Brain Res., 2006, 173, 76.

17 X. Ying, H. Wen, W. L. Lu, J. Du, J. Guo, W. Tian, Y. Men, Y. Zhang, R. J. Li, T. Y. Yang, D. W. Shang, J. N. Lou, L. R. Zhang and Q. Zhang, J. Controlled Release, 2010, 141, 183.

18 H. Ding, V. Sagar, M. Agudelo, S. Pilakka-Kanthikeel, V. S. Atluri, A. Raymond, T. Samikkannu and M. P. Nair, Nanotechnology, 2014, 25, 055101.

19 H. Xaio, W. Banks, M. L. Niehoff and J. Morley, Brain Res., 2001, 896, 36.

20 P. Wang, Y. Xue, X. Shang and Y. Liu, Cell. Mol. Neurobiol., 2010, 30, 717.

21 D. Camerino, P. M. Conway, B. I. J. M. van der Heijden, E. van der Schoot, J. Pokorski, M. Estryn-Behar and H. M. Hasselhorn, Int. Congr. Ser., 2005, 1280, 61.

22 T. J. Abbruscato, S. P. Lopez, K. S. Mark, B. T. Hawkins and T. P. Davis, J. Pharm. Sci., 2002, 91, 2525.

23 X. Wei, C. Zhan, Q. Shen, W. Fu, C. Xie, J. Gao, C. Peng, P. Zheng and W. Lu, Angew. Chem., Int. Ed., 2015, 54, 3023.

24 X. Wei, C. Zhan, X. Chen, J. Hou, C. Xie and W. Lu, Mol. Pharmaceutics, 2014, 11, 3261.

25 T. R. Pearce, K. Shroff and E. Kokkoli, Adv. Mater., 2012, 24, 3803.

26 J. A. Barreto, W. O'Malley, M. Kubeil, B. Graham, H. Stephan and L. Spiccia, Adv. Mater., 2011, 23, H18.

27 H. Yan, L. Wang, J. Wang, X. Weng, H. Lei, X. Wang, L. Jiang, J. Zhu, W. Lu and X. Wei, ACS Nano, 2011, 6, 410.

28 J. Li, P. Cai, A. Shalviri, J. T. Henderson, C. He, W. D. Foltz, P. Prasad, P. M. Brodersen, Y. Chen and R. DaCosta, ACS Nano, 2014, 8, 9925.

29 R. Qiao, Q. Jia, S. Hüwel, R. Xia, T. Liu, F. Gao, H.-J. Galla and M. Gao, ACS Nano, 2012, 6, 3304.

30 X. Wang, T. Ishida and H. Kiwada, J. Controlled Release, 2007, 119, 236.

31 T. Ishida, X. Wang, T. Shimizu, K. Nawata and H. Kiwada, J. Controlled Release, 2007, 122, 349.

32 T. Ishida and H. Kiwada, Int. J. Pharm., 2008, 354, 56.

33 Y. Liu, H. Reidler, J. Pan, D. Milunic, D. Qin, D. Chen, Y. R. Vallejo and R. Yin, J. Pharmacol. Toxicol. Methods, 2011, 64, 238.

34 Y. Hashimoto, T. Shimizu, A. S. Abu Lila, T. Ishida and H. Kiwada, Biol. Pharm. Bull., 2015, 38, 417.

35 M. J. Haney, N. L. Klyachko, Y. Zhao, R. Gupta, E. G. Plotnikova, Z. He, T. Patel, A. Piroyan, M. Sokolsky, A. V. Kabanov and E. V. Batrakova, J. Controlled Release, 2015, 207, 18.

36 M. Sakakida, K. Nishida, M. Shichiri, K. Ishihara and N. Nakabayashi, Sensors and Actuators B, 1993, 319, 13-14.

37 K. Ishihara, Y. Abe, S. Enomoto, A. Watanabe, S. Tanaka and N. Nakabayashi, Biomedical Materials Research in the Far East (1), Kobunshi Kankokai, Kyoto, 1993, p. 7.

38 T. Yoneyama, K. Ishihara, N. Nakabayashi, M. Ito and Y. Mishima, J. Biomed. Mater. Res., 1998, 43, 15.

39 K. Ishihara, T. Shinozuka, Y. Hanazaki, Y. Iwasaki and N. Nakabayashi, J. Biomater. Sci., Polym. Ed., 1999, 10, 271.
40 M. Kyomoto, T. Moro, Y. Iwasaki, F. Miyaji, H. Kawaguchi, Y. Takatori, K. Nakamura and K. Ishihara, J. Biomed. Mater. Res., Part A, 2009, 91, 730.

41 Y. Iwasaki, S.-i. Sawada, N. Nakabayashi, G. Khang, H. B. Lee and K. Ishihara, Biomaterials, 1999, 20, 2185.

42 S. Chen, J. Zheng, L. Li and S. Jiang, J. Am. Chem. Soc., 2005, 127, 14473.

43 Y. He, J. Hower, S. Chen, M. T. Bernards, Y. Chang and S. Jiang, Langmuir, 2008, 24, 10358.

44 Q. Shao and S. Jiang, Adv. Mater., 2015, 27, 15.

45 B. Gao, Y. Feng, J. Lu, L. Zhang, M. Zhao, C. Shi, M. Khan and J. Guo, Mater. Sci. Eng. C, 2013, 33, 2871.

46 B. Wang, T. Jin, Y. Han, C. Shen, Q. Li, Q. Lin and H. Chen, J. Mater. Chem. B, 2015, 3, 5501.

47 S. Sawada, Y. Iwasaki, N. Nakabayashi and K. Ishihara, J. Biomed. Mater. Res., Part A, 2006, 79, 476.

48 T. Goda, T. Konno, M. Takai, T. Moro and K. Ishihara, Biomaterials, 2006, 27, 5151.

49 J. Sibarani, M. Takai and K. Ishihara, Colloids Surf., B, 2007, $54,88$.

50 H. Ueda, J. Watanabe, T. Konno, M. Takai, A. Saito and K. Ishihara, J. Biomed. Mater. Res., Part A, 2006, 77, 19.

51 A. Bakhai, J. Booth, N. Delahunty, F. Nugara, T. Clayton, J. McNeill, S. W. Davies, D. C. Cumberland, R. H. Stables and S. V. S. Investigators, Int. J. Cardiol., 2005, 102, 95.

52 J. Watanabe and K. Ishihara, Biomacromolecules, 2005, 6, 1797.

53 S. Abraham, S. Brahim, K. Ishihara and A. Guiseppi-Elie, Biomaterials, 2005, 26, 4767.

54 T. Konno, H. Hasuda, K. Ishihara and Y. Ito, Biomaterials, 2005, 26, 1381.

55 R. R. Palmer, A. L. Lewis, L. C. Kirkwood, S. F. Rose, A. W. Lloyd, T. A. Vick and P. W. Stratford, Biomaterials, 2004, 25, 4785.

56 S. Long, Biomaterials, 2003, 24, 4115.

57 H. K. Avraham, S. Jiang, T. H. Lee, O. Prakash and S. Avraham, J. Immunol., 2004, 173, 6228.

58 H. Pu, J. Tian, I. E. Andras, K. Hayashi, G. Flora, B. Hennig and M. Toborek, J. Cereb. Blood Flow Metab., 2005, 25, 1325.

59 I. E. Andras, H. Pu, J. Tian, M. A. Deli, A. Nath, B. Hennig and M. Toborek, J. Cereb. Blood Flow Metab., 2005, 25, 1159.

60 K. S. Rao, M. K. Reddy, J. L. Horning and V. Labhasetwar, Biomaterials, 2008, 29, 4429.

61 I. E. András, H. Pu, M. A. Deli, A. Nath, B. Hennig and M. Toborek, J. Neurosci. Res., 2003, 74, 255.

62 R. Yu, Z. Zeng, X. Guo, H. Zhang, X. Liu, Y. Ding and J. Chen, Neurosci. Lett., 2012, 527, 1.

63 M. J. Simon, S. Gao, W. H. Kang, S. Banta and B. Morrison, 3rd, Biotechnol. Bioeng., 2009, 104, 10.

64 Y. Qin, H. Chen, W. Yuan, R. Kuai, Q. Zhang, F. Xie, L. Zhang, Z. Zhang, J. Liu and Q. He, Int. J. Pharm., 2011, 419, 85.

65 Y. Qin, H. Chen, Q. Zhang, X. Wang, W. Yuan, R. Kuai, J. Tang, L. Zhang, Z. Zhang, Q. Zhang, J. Liu and Q. He, Int. J. Pharm., 2011, 420, 304.

66 H. Brooks, B. Lebleu and E. Vives, Adv. Drug Delivery Rev., 2005, 57, 559. 
67 W. A. Banks, S. M. Robinson and A. Nath, Exp. Neurol., 2005, 193, 218.

68 M. Yan, J. Du, Z. Gu, M. Liang, Y. Hu, W. Zhang, S. Priceman, L. Wu, Z. H. Zhou and Z. Liu, Nat. Nanotechnol., 2010, 5, 48.
69 J. Zhang, Y. Lei, A. Dhaliwal, Q. K. Ng, J. Du, M. Yan, Y. Lu and T. Segura, Biomacromolecules, 2011, 12, 1006.

70 S. Nakagawa, M. A. Deli, H. Kawaguchi, T. Shimizudani, T. Shimono, A. Kittel, K. Tanaka and M. Niwa, Neurochem. Int., 2009, 54, 253. 